\title{
Compact Force Effects of Canvas Stretched Woven Fabrics and the Angle-view on the Philosophy of Painting "Ages" of Artist's Sergi Cadenas
}

\author{
Elsayed Ahmed Elnashar \\ Home Economice Department, Faculty of Specific Education, Kaferelsheikh University, Kaferelsheikh City, Egypt
}

\section{Email address:}

smartex@kfs.edu.eg

\section{To cite this article:}

Elsayed Ahmed Elnashar. Compact Force Effects of Canvas Stretched Woven Fabrics and the Angle-view on the Philosophy of Painting "Ages" of Artist's Sergi Cadenas. American Journal of Art and Design. Vol. 5, No. 1, 2020, pp. 1-11. doi: 10.11648/j.ajad.20200501.11

Received: December 30, 2019; Accepted: January 7, 2020; Published: April 28, 2020

\begin{abstract}
The new approach being developed for modeling the philosophy of painting "ages" of artist's Sergi Cadenas the progressive aging of face skin of human body society caused by profound demographic changes, While the structure design and behavior of fabric structures creation of shapes and images is relatively easy, accurate control of painting color/weave rendering of intimately blended painting pre-colored yarns is a critical and difficult to control attribute. brings with it the necessity of confronting the subject of painting "ages", that can influence society's attitudes regarding this population, in addition to impacting the self-perception of compact force effects of canvas fabrics on painting young to elderly people. an aim of this paper is to propose fabrics and the angle-view on the philosophy of painting "ages" of artist's Sergi Cadenas theory applied the concept of compact force to flexibility, geometry shape objects described for stretch clothes design often consists of complex objects the current painting progress in developing models combining painting colors/weaves and geometry of canvas multi-layer woven structure design and compact force behavior of canvas fabrics. The compact force effects and the angle-view, in turn have consequences for positive outcomes during the aging on painting process, and discussing a compact force as dynamic behavior of stretch clothes in painting surfaces. Thereby reducing or even eliminating the need for physical sampling prior to production, and investigate the simultaneous relationships between compact force effects as stretch potentials knowledge the angle-view and, age, anxiety about aging, and stereotypes toward the elderly, as well as their predictive roles with respect to process painting ageism. Based on the analyses conducted, anxiety about compact force effects of fabrics and the angle-view knowledge are antecedents for stereotypes on philosophy of painting "ages" of artist's Sergi Cadenas, stretch potentials of canvas fabrics which in turn, together with the other variables, influence ageism. Increased education about the aging painting process could help reduce anxiety and stereotypes repetitions the painting aging's was most responsible for the angle-view. Knowledge of the antecedents of compact force effects of fabrics and the angle-view on painting toward the effect is included in the form of life stages is fundamental to promoting positive attitudes toward them.
\end{abstract}

Keywords: Compact Force, Canvas Fabrics, Angle-View, Painting, Ages, Artist's Sergi Cadenas

\section{Introduction}

For analyzing knowledge representation, compact force effects of fabrics theory applied an information system which is defined as a finite information yarns [10,9], the fabrics structures of which are labeled by objects, the compact force of two-component structures of canvas multilayered woven fabrics provide many possibilities for painter to vary the appearance of painting; introduce features such as bulk, stretch and abrasion resistance; produce lining less painting with good hygienic properties; and combine special painting functions with ergonomic factors.

\subsection{Compact Force Theory}

To introduce concept canvas woven fabrics of compact force theory as multi-layer woven fabric consists of two canvas layers $[9,10]$, which are woven one above the other and stitched together of aesthetics wrinkled [16]. In compact force theory, an information system is based on the decision table, which is theoretically same as relational database of double 
woven fabric contains two systems of warp, face and back, and two systems of weft for compact force using compact force theory of geometry shape objects described for stretch clothes design has more flexible information structure. The fabric can be called either two-ply fabric or double fabric. Compact force interlaced the face warp threads with the face weft threads forms upper canvas fabric layer and the compact force interlaced the back warp threads with the back weft threads forms the canvas lower fabric layer of the double fabric. Twocomponent canvas multilayered fabrics are woven using two interlaced weaves: main and lining. The main weave, which forms the outer surface, gives the desired appearance of the fabric and provides its stretch and abrasive resistance, it does not take into account the compressibility of threads and their deformations which occur in contact with other threads and due to their interlacing, and simplifies the shape of the parts of threads to be rectangular $[9,10]$.

\subsection{Artist's Sergi Cadenas}

Sergi Cadenas is a Spanish postwar \& contemporary artist who was born in 1972. Born at Girona in 1972 to a family associated for generations with crafted ironwork, Cadenas is a vocational artist whose creativity follows his own self-taught premises. Experimentation has afforded him a visual language of his own. In his recent oeuvre, three-dimensional oil paintings vary depending on the viewer's perspective, introducing a kinetic, disturbingly suggestive dimension to our vision of reality. His work has earned credible attention. [1]

Cadenas' artistic development has always been linked to the world of the artisan. He studied design and artistic ironmongery in the Gremi de Serrallers in Barcelona, and even though he is a skilled painter, he has never studied drawing and is entirely self-taught. Nowadays, he is responsible for Ferros d'Art Cadenas, the family business, a well-known company in Girona which has been around for almost three centuries. Since his predecessors moved there in the first half of the 19th century, the foundry has been an essential part of the cultural and architectural history of the city. Sergi's great-grandfather, Nonito, worked with the architect Rafel Masó, and his wrought-iron work can be seen in more than one of Masó's constructions. Sergi has continued the family trade, and he is now a recognized artisan who is specialised in forging techniques. He also works and collaborates with different architects from Girona. For family tradition, he dedicates to the artistic forge, work that combines with his great passion, artist painter, to which he has arrived in a totally self-taught way. The desire to experiment and discover new ways of creating, have led him to paint three-dimensional works on oil, which depending from which angle you look at, the image changes. Currently he is focused in portraits of large format made with this difficult execution technique and with great precision. [1]

\subsection{Light in the Paintings of the Impressionist}

Philosophy critic named movement in response to philosophy Monet's painting in 1st Impressionist show in
1874. By 3rd show in 1878 , the artists embraced their title. Before the term was used for sketches, whose qualities apply to impressionist paintings [19]: abbreviation, speed, spontaneity, sensation, impermanence, and the "fleeting moment" artists' sensations, subjective and personal responses to nature. The traditional subjects and polished technique, philosophy created more paintings of from the same view at different times of day, under various climatic conditions of aesthetics wrinkled, with scientific precision, he carefully recorded the passing of time as seen in the movement of light over identical forms which focused on light and color to reach a greater understanding of appearance throw aesthetics wrinkled fabrics and which languages that colors speaking in fashion textiles/clothes contemporary fashion and its artistic values in the fifth generation of technology, $[14,15,16]$.

\subsection{Canvas Woven Fabrics}

Canvas is an extremely durable plain-woven fabric used for making sails, tents, marquees, backpacks, and other items for which sturdiness is required, as well as in such fashion objects as handbags, electronic device cases, and shoes. It is also popularly used by artists as a painting surface, typically stretched across a wooden frame. Modern canvas is usually made of cotton or linen, along with polyvinyl chloride, although historically it was made from hemp. aesthetics wrinkled it differs from other heavy cotton fabrics, such as denim, in being plain weave rather than twill weave. Canvas comes in two basic types: plain and duck. The threads in duck canvas are more tightly woven throw aesthetics wrinkled [16]. The canvas is classified in two ways: by weight; ounces per square yard and by a graded number system. The numbers run in reverse of the weight so number 10 canvas is lighter than number 4 of aesthetics wrinkled of canvas has become the most common support medium for oil painting, replacing wooden panels. It was used from the 14th century in Italy, but only rarely. One of the earliest surviving oils on canvas is a French Madonna with angels from around 1410 in the Gemäldegalerie, Berlin. The word "canvas" is derived from the 13th century Anglo-French canevaz and the Old French canvas. Both may be derivatives of the Vulgar Latin cannapaceus for "made of hemp", originating from the Greek. [20, 22, 24, 30] So we can see canvas of between ancient Egyptian history and future [13]

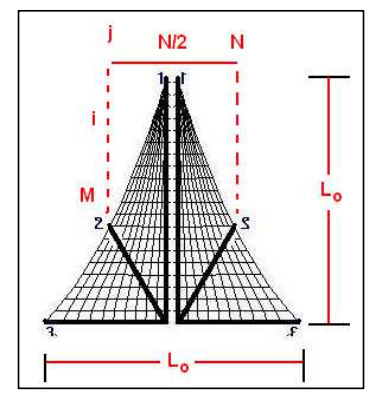

Figure 1. Top view of the fabric lay on the frame to be deformed. 


\subsection{Compact Force Models}

Aesthetics wrinkled of compact force mathematical models were worked into different structures throw aesthetics wrinkled of canvas double layers of woven with different assumptions [16]. In these models, the kind of deformation occurring with the effect of spatial force acting upon a fabric placed on a square frame was studied. The main assumptions here were the spandex yarn elongation, the intersection angles between the canvas layers and yarns systems, and during the deformation period, because of spandex yarn elongation, a faces shape like: Round, Oval, Square, Rectangle, Diamond and Heart shaped face having occurred. So the compact force needed for deformation was calculated with the Canvas double layers of woven fabrics throw of aesthetics wrinkled. The conditions that these computer programs symbolize in general are represented in figure 1. [9, 10], where: L0: The side length of the square frame in which the fabric is placed, $\mathrm{N}$ : The number of the warp yarns in the frame, M: The number of the weft yarns in the frame, N/2: The number of the warp yarns to the middle point of the frame, $\mathrm{j}$ : The warp indices the weft indices aesthetics wrinkled of understanding how panels are created, and being certain which way up they are compact force of surface has been designed to be as easy to use as possible $[9,10]$. Throughout the program, the intention has been to make it possible for the user to create their structure with a minimum of key presses or button clicks, to achieve this aim, it has been necessary to make some relatively arbitrary choices about how certain parts of the software should work. This is particularly so in that part of the software that deals with creating faces. In order to minimize the choices that had to be made, and to streamline the process, a couple of specific conventions have been built into the software: [10]

1) Aesthetics wrinkled of the two aesthetics wrinkled lines that make up the edges of a given panel, the stitch line with the lower number is deemed to be the left-hand side of the panel.

2) aesthetics wrinkled of each stitch type is deemed to run in a particular direction: horizontal Stitch s run left-to-right, vertical stitch s run top-to-bottom, right diagonal aesthetics wrinkled run from top left to bottom right, left diagonal stitch s run from bottom left to top right, and geodesic Stitch run in the direction in which they were created. Let us examine what these conventions actually mean, and what affect they have on the actual panel-creation process. Consider the tent portion below: Tent portion with aesthetics wrinkled defined on it; the dark lines represent the aesthetics wrinkled. When surface calculates the panels defined by this aesthetics wrinkled (1) is deemed to be the left-hand side of the panel, and stitch 2 the right-hand side. Next, it is necessary to find the start points of the stitch. The fundamentals of the geometric assumptions of the computer program are shown in Figure 2(a), (b) and (c). As will be seen in Figure 1(b) $[9,10]$.,

$$
\mathrm{L}_{\mathrm{n} / 2}=\left(\frac{\operatorname{sine} \alpha \sqrt{\left(L_{o} / 2\right)^{2}+D^{2}}}{D}\right) D / L_{o / 2}
$$

Can be detrained So

$$
\left(\frac{\frac{j}{N / 2}}{\frac{l_{o j}}{L_{o / 2}}}\right)-\left(\sqrt{\frac{j}{N}}\right)+\frac{2 j+l_{j}}{N}
$$

$j:$ The sequence of any warp yarn, $l_{o j}$ : The initial length of any one of the warp yarns $l_{j}$ : The length of any one of the warp yarns after deformation, and $\mathrm{N} / 2$, figure 2 Geometric assumptions forming the fundamentals of aesthetics wrinkled by the computer programs (a) Distribution of the pressing force, (b) Position at the perpendicular cross-section after deformation, $\mathrm{L} 0=2$ : The length until the middle point of the frame side, $\mathrm{Ln}=2$ : The length of the yarn until the middle point of the frame side after deformation as aesthetics wrinkled, (c) Comparison between before and after deformation (Top view) The all results in a panel as below:

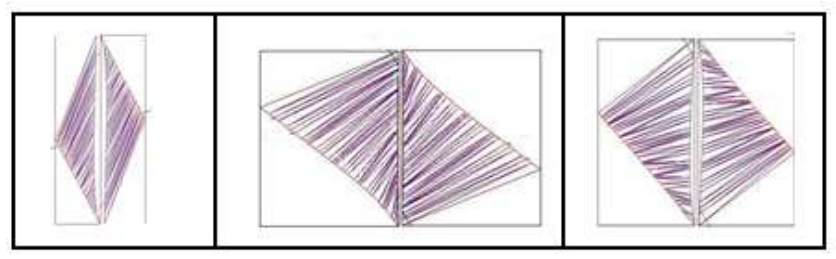

Figure 2. (a), (b) and (c). Panel produced from the tent region between aesthetics wrinkled 1 and 2 [9, 10].

Similarly, the second panel between stitches 2 and 3 has aesthetics wrinkled 2 on the left-hand side, aesthetics wrinkled three on the right-hand side, and has the start points of the aesthetics wrinkled at the bottom of the panel, and the panel produced from the tent region between aesthetics wrinkled 2 and 3

\subsection{The Angle-View}

To overcome the limitation of viewing angle some methods have been studied throw aesthetics wrinkled [16], one method is using a Fresnel lens array that has a small fnumber to widen the viewing angle [27].

However, there is limitation in decreasing the f-number and there occurs the lens aberration. Another method is using lens switching to enhance the viewing angle by doubling the region of each elemental image $[6,31]$. This approach of aesthetics wrinkled fabrics [16], however, needs a mechanical mask that should move fast enough for the afterimage effect, which causes some problems such as air resistance and noise [31]. To implement the dynamic mask without mechanical movement, another method using orthogonal polarization switching was proposed [25]. This method uses orthogonally polarized elemental images with polarization shutter screen and the orthogonal polarization sheet attached to the lens array. The disadvantage of this method is that the intensity of original image is reduced by half with using the polarization sheet and the integrated image becomes dim. The method which uses volume holographic recording of the elemental images [26] has been 
proposed also. However, the method cannot implement dynamic color display. Another method which uses moving lens let arrays with low fill factor [21] was also proposed, but the system needs mechanical movement. Another method is the idea that is using multiple display devices [5, 28, 31]. However, structure aesthetics wrinkled is bulky and tested only for the double-device case.

\section{Experimental Work}

Materials and weave structures to verify on canvas doublelayers of weave/color combination constructed for the validation purpose.

\subsection{Fabric Production}

Double fabrics (two layers) were produced using the SA STAUBLI machine, the type of machine SULZER NOUVA, which is an Italian industry, width of $360 \mathrm{~cm}$, and the Jacquard type SUTBLE Model JC, French industry, with stretch of 2655 Schenl, and the fabric was in Mahalla Al-Kubra, Egypt.

\subsection{Woven Fabric Structures}

The upper layer is plain weave $1 / 1$, and the lower layer is plain weave $1 / 1$, and the weave of cohesion fabric is satin weave 5. Cohesion in double fabrics is the cohesion of warp. Double fabrics containing spandex weft, which were spun, and folded yarn (30/2 English count) as Direct system (39.367 Tex) were produced at Misr Company in Mahala, Egypt. And its data: Spandex thread covered with single cotton. Constructions the cotton yarns and a general process of scouring process suitable for most of the fabrics containing spandex comprises fabric relaxation followed by scouring, exhaustion technique was employed to affect by using scouring machine, scouring processes under conditions commonly used for spandex fabrics according AATCC Standard Test Method, D-79-1968. [2], ASTM D 3776-96 standard test method for mass per unit area (Weight) of fabric. [3], the thickness was measured by thickness mm by ElNashar Digital Thickness Test Method ${ }^{\circledR}$. [7], ASTM D3107-2003 (standard test method for stretch properties of fabrics woven stretch yarn). [4], and stiffness for stretch woven fabrics according to standard test method ASTM. D1388-96 (standard test method for stiffness of fabrics). [29].

Fabric of Canvas For painting structure aesthetics wrinkled of canvas has become Fabrics on which oil paintings and drawing, the most common support medium for oil painting, replacing wooden panels that was used from the 14th century in Italy, another common category of paintings on lighter cloth such as linen was in distemper or glue, often used for banners to be carried in procession. This is a less durable medium and surviving in distemper on linen are rare, and often rather faded in appearance. Canvas are stretched woven fabrics on which oil paintings and drawing is typically stretched across a wooden frame called a stretcher and may be coated with gesso before it is to be used; stretch potential of stretched woven fabrics, this is to prevent oil paint from coming into direct contact with stretch potential of the canvas fibers, which will eventually cause the canvas to decay. canvas double-layers of weave/color a traditional and flexible chalk gesso is composed of lead carbonate and linseed oil, stretch potential is applied over a rabbit skin glue ground; a variation using titanium white pigment and calcium carbonate is rather brittle and susceptible to cracking. As lead-based paint is poisonous, care has to be taken in using it.

Canvas was made of linen as double-layers of weave/color; a sturdy brownish fabric of considerable stretch linen is particularly suitable for the use of oil paint. In the early 20th century, cotton canvas, often referred to as "cotton duck", and came into use. Linen double-layers of weave/color are composed of higher quality material, and remain popular with many professional artists, especially those who work with oil paint. Cotton double-layers duck which stretches more fully and has an even, mechanical weave, offers stretch potentials a more economical alternative. The advent of acrylic paint has greatly increased the popularity and use of cotton duck canvas. Linen and cotton double-layers of weave/color derive structure aesthetics wrinkled from two entirely different plants, the flax plant and the cotton plant, respectively. They are prepared with two or three coats of gesso and are ready for use straight away of cotton double-layers. Artists desiring greater control of their painting surface may add a coat or two of their preferred gesso. Professional artists who wish to work on canvas double-layers may prepare their own canvas in the traditional manner. One of the most outstanding differences between modern painting techniques and those of the preparation of the canvas. Stretch potentials as modern techniques take advantage of both the canvas texture as well as those of the paint itself. Renaissance took extreme measures to ensure that none of the face shape of the canvas came through. This required a painstaking, monthslong process of canvas layering the raw canvas with usually lead-white paint, then polishing the surface, and then repeating. Stretch potentials as modern techniques of canvas woven fabrics of double layer starting with this article from the end year 2019 onward, canvas was used as a covering canvas double layer woven fabrics on stretch potentials as modern techniques. The canvas was applied to cover with multiple layers of gesso and often richly painted in tempera technique. And the surfaces were sealed with a transparent varnish. Stretch potentials as modern techniques as splined canvases differ from traditional side-stapled canvas in that canvas is attached with a spline at the rear of the frame. This allows the artist to incorporate painted edges into the artwork itself without staples at the sides, and the artwork can be displayed without a frame. Splined canvas can be rest retched throw stretch potentials by adjusting the spline. Stapled canvases stay stretched throw stretch potentials tighter over a longer period of time, but are more difficult to re-stretch when the need arises. Structure aesthetics wrinkled of the canvas is typically linen primed for a certain type of paint and stretch potentials as new technic. They are primarily used by artists for quick studies stretch potentials as new technic, and then canvas types are: dyed, fire-proof, printed, stripe, water-resistant, 
waterproof, waxed and rolled.

\section{Results and Discussions}

Fabric's results, the total number of samples produced utilizing the simple weaves is 8 specimens of stretch potential shapes design.

Table 1. Specifications of yarns and on-loom fabric count utilized to construct stretch potential the simple weaves and angle value.

\begin{tabular}{|c|c|c|c|c|c|c|}
\hline No & wide on Loom & Wide off loom & Wide after relaxation & stretch potential & Face cod & Angle value \\
\hline 1 & \multirow{6}{*}{260} & 247 & 247 & 0,030 & A & $0^{\circ}$ \\
\hline 2 & & 236 & 228 & 0,043 & B & $4.2^{\circ}$ \\
\hline 3 & & 237 & 229 & 0,053 & $\mathrm{C}$ & $6.1^{\circ}$ \\
\hline 5 & & 247 & 247 & 0,070 & $\mathrm{E}$ & $9.5^{\circ}$ \\
\hline 6 & & 236 & 229 & 0,081 & $\mathrm{~F}$ & $13^{\circ}$ \\
\hline 7 & & 236 & 229 & 0,090 & G & $16.5^{\circ}$ \\
\hline
\end{tabular}

The warp and filling yarns specifications and fabric count used for the preparation of 8 artwork weave stretch potential structures of figures 3 and 4 are shown in table 1 . The stretch potential were arranged in sequential order of one green, one yellow, one red, and one blue. While the weft yarns were arranged one white of spandex cotton/spandex as single covered, as the following weave structures:

\subsection{Images of Stretch Potential on Fabrics}

In figure 3 , illustrated faces design of compact force (A) 0,030 , and in (B) fabric by using weft 2 : stretch potential of compact force 0,043 , and $(C)$ by using weft 1 : stretch potential 0,053 , then the balance while using spandex wefts with circle faces one side is a mirror image of the other side things just looks right, and more exciting and dramatic of wrinkle in fabric. So, compact force is refers to how attention is led around the artwork or the outfit, compact force is achieved when the lines, shapes, colors, wrinkle face shapes of wrinkles are arranged to lead the viewer's eye easily from one part of the artwork to another. And compact force of thin at top to thick strips, small at top to large down In figure 3, illustrated faces design (D), and in (B) fabric by using weft 1: stretch potential 0,043 , by using weft 2 : stretch potential 0,062 , the emphasis while using spandex wefts with circle faces creates a center of interest, also referred to as a focal point. A dominant focal point or center of interest in a wrinkle painting or an outfit created by the use of line, shape, color, wrinkle face shape and an outfit without a dominant point of interest appears uninteresting, boring, and unfinished. Two or more dominant areas or points of emphasis are distracting wrinkle and confusing the eye becomes overly stimulated and the effect is spotty and displeasing.

- Harmony compact force while using spandex wefts with circle faces creates a center of aesthetics interest; compact force is achieved when unity and variety are effectively combined, we can obtain "aesthetics-unity": the design is seen as "whole". force-unity can be achieved through matching and coordinating, and "compact force-variety": refers to the use of lines, shapes, colors, aesthetics wrinkle Face shapes and faces with enough variety to avoid boredom, but not so much variety as to create conflict. unity "things that are alike" a sense of completeness, when nothing is missing, left out or undone both can be overdone, the key is to balance both to achieve aesthetics harmony.

- Emphasis compact force while using spandex wefts creates a gravity aesthetics wrinkle of center interest also referred to as a circle focal point. In figure 4, illustrated faces design (A), and in (B) fabric by using weft 1: stretch potential, and (C) and (D) weft 2: stretch potential, a dominant focal point or center of interest gravity aesthetics wrinkle in canvas for a painting or an outfit created by the use of line, shape, color, gravity aesthetics wrinkle of face shape, and two or more dominant areas or points of Compact emphasis force are distracting and confusing the eye becomes overly stimulated and the effect is spotty and displeasing.

\subsection{Compact Angle Potential}

In figure three and four, compact force illustrated faces design (E) stretch potential 0,070 , and in (F) 0,081 fabric by using weft 1: stretch potential of compact force, and $(\mathrm{G})$ stretch potential 0,090 and $(\mathrm{H})$ stretch potential 0,102 weft 2 : stretch potential, harmony is achieved while using spandex wefts when unity and variety are effectively combined. The design is seen as"whole", and stretch potential of compact force-unity can be achieved through matching and coordinating, so stretch potential harmony force variety can relieve monotony by giving the eye a number of different details to look at refers to the use of lines, shapes, colors, aesthetics face shapes with enough variety to avoid boredom, but not so much variety as to create conflict. While verity "Things that are different" when the design has differences to create interest. Then unity a sense of completeness, when nothing is missing, left out or undone both can be overdone, the key is to balance both to achieve aesthetics harmony. We calculate the dimensions of the woven sample before and after wet relaxation were used to calculate the stretch potential using Equations 1 and 2. Compact Angle Potential \% in length (warp) direction, as throw in figure 2, the illumination of an elemental surface on the canvas stretched woven fabrics defined by a radius $r$ and azimuth angle $\varphi$ is given by (Compact Angle Potential):

$$
C A P 1+\frac{E(r,+\varphi) r d r}{1}+\frac{n\left(S P_{W, \varphi()_{2}^{2}}{ }^{+n-1) x^{2}}\right.}{2}+l(\theta, \varphi) \operatorname{Sxin}(\theta) \cos (\theta) d o
$$


$\mathrm{L}(\theta, \varphi)$ is the luminance of the object and $\mathrm{S}$ the surface analyzed by the canvas stretched woven fabrics optics. Maximum Stretch Potential \% in canvas stretched woven fabrics as width (weft) direction $[9,10,22]$,

$$
S P_{W, \max }=\frac{W_{\text {on-loom }}-W_{\text {relaxed }}}{W_{\text {on-loom }}} \times 100
$$

Here Lon-loom and Won-loom are the length and width of the on-loom fabric. $\mathrm{L}$ relaxed and $\mathrm{W}$ canvas stretched woven fabrics relaxed is length and width of the canvas stretched woven fabrics samples after wet relaxation. The target stretch dimensions at which the woven samples would be heat-set were calculated using Equation 3. Fabric dimensions at target stretch of $\mathrm{y} \%[9,10,22]$

$$
W_{y \%}=W_{\text {on-loom }}-\frac{\left(y * W_{\text {on-loom }}\right)}{100}
$$

\subsection{Compact Colour Values of Canvas Stretched Potential}

Yarn mass per length unit, threads density, stretch potential and weave determine the size and the shape of the stretch surfaces on canvas stretched woven fabrics [9, 10, 12, 22], which are covered with warp and weft threads, stretch potential geometrical models of plain weave, with the warp interlacing point- $\mathrm{w}$ and the weft interlacing point-f. canvas stretched woven fabrics throw Colour surfaces of compact force and viewing angle are warp-1, weft-2 and space between threads; the diameters of the warp and weft threads, and $1 / \mathrm{gw}$ and $1 / \mathrm{gf}$ the spaces between interlacing point surface is calculated from the geometrical model of compact force and viewing angle [11]. With further analysis compact force and viewing angle interlacing point geometry the fractions of individual colour surfaces are mathematically defined with regard to the entire colour repeat. The surfaces are defined by considering the colour and the place of appearance in the fabric. The geometry of the compact force and viewing angle with larger repeat differs from plain weave in the size of colour repeat, which means in the number of the warp and stretch weft interlacing points in the smallest colour repeat unit. Wavelengths are defined with chemical and optical properties of the substrate. If reflectance R (\%) and colour values $\mathrm{L}^{*}, \mathrm{a}^{*}, \mathrm{~b}^{*}$ of the warp threads-w and compact force and viewing angle potential of weft threads- $f$ and substrate- $p$ are considered, the reflectance and $L * a * b *$ values of a fabric can be expressed with Equations (6) to (9). $S P_{W \%}$ the ratio compact force potential of surface and compact force throw weft direction, [9, 12, 22].

$$
\begin{gathered}
\mathrm{R}_{t k(\lambda)}=\left(R_{w} u_{w}\right)_{(\lambda)}+\frac{\left(R_{f} u_{f}\right)}{S P_{W \%}}+\left(R_{p} u_{p}\right)_{(\lambda)} \\
L^{*}{ }_{t k}=\left(L{ }_{w}{ }_{w} u_{w}\right)+\frac{\left(L{ }_{f} u_{f}\right)}{S P_{W \%}}+\left(L{ }_{p}{ }_{p} u_{p}\right) \\
a^{*}{ }_{t k}=\left(a^{*}{ }_{w} u_{w}\right)+\left(a^{*}{ }_{v} u_{v}\right)+\left(a^{*}{ }_{p} u_{p}\right) \\
b^{*}{ }_{t k}=\left(b^{*}{ }_{w} u_{w}\right)+\frac{\left(b^{*}{ }_{f} u_{f}\right)}{S P_{W \%}}+\left(b^{*}{ }_{p} u_{p}\right)
\end{gathered}
$$

Where $\mathrm{d}=$ Yarn diameter in $\mathrm{cm}, \mathrm{Nt}=$ Yarn number in tex $(\mathrm{g} / \mathrm{km}), \rho \mathrm{f}=$ Fiber density $\left(\mathrm{g} / \mathrm{cm}^{3}\right), \rho \mathrm{y}=$ Yarn density $\left(\mathrm{g} / \mathrm{cm}^{3}\right)$ $[9,10]$

$$
\text { Yarn packing fraction (or factor) }=\phi=\frac{(\rho \mathrm{y})}{(\rho \mathrm{f})}=\frac{\text { Yarn density }(\mathrm{g} / \mathrm{cm} 3)}{\text { Fiber density }(\mathrm{g} / \mathrm{cm} 3)}
$$

\subsection{Compact Force in faces of Triangular, Rectangular and Circle}

Triangular, Rectangular and circle faces are the face of the original elements of artwork into three smaller during this all- quad compact force and viewing angle mesh conversion, of warp and weft yarns that appears on the fabric compact faces, which is a function of the constructional parameters. To predict contribution of each colors/weaves to surface and compact force and viewing angle [8, 9, 10, 12], we considered idealized fabric geometry with the following assumptions to simplify calculations since real fabric construction parameters are rather complex in their shape:

1. Yarns' diameters are surface and compact force uniform cylinders.

2. Warp spacing at the weave intersection and under the float is constant.

3. Pick spacing at the weave intersection and under the float is surface and compact force constant.

4. The projection surface and compact force twodimensional of the fabric on a plane parallel to fabric plane is considered.

5. Yarns' are uniformly surface and compact force of colored/weaves.

The resultant proportions of surface and compact force colors/weaves present on the surface of the woven design are calculated for the repeat that represents an entire region in the Jacquard design.

\subsection{Viewing Angle}

To investigate the effect of compact force and viewing angle, we compare the integrated image of painting "ages" the conventional scheme with that of the proposed scheme. Figure 7 shows integrated painting observed from different viewing directions in the conventional and the proposed schemes of stretch potential throw structure aesthetics wrinkled the observed image of painting "ages" right viewing region which is not shown in Figure 7 . Is similar to that of left result because the viewing region is symmetric. In the conventional scheme the theoretical compact force effects and viewing angle for the lens specification is $9.5^{\circ}$ [22] along 
one side and the effective angle is $7.5^{\circ}$ (one-side) experimentally. From $7.5^{\circ}$, some portions of the face stretch potential image disappear. We can see that at left $10^{\circ}$ the original image disappears and the flipped image appears. As the observation angle increases more, the flipped images appear more as shown in conventional scheme of stretch potential throw aesthetics wrinkled Figure 7 and around $13^{\circ}$ we can observe the flipped image only. In the proposed scheme, however, we can see the integrated image even beyond the conventional viewing angle as shown in the proposed scheme in Figure 2 and 3, with increasing observation angle, however, the images are not integrated well due to the gap mismatch as shown in left $20^{\circ}$ of the proposed scheme in Figures 3, 4, shows that the effective viewing angle is $16.5^{\circ}$ (one-side) experimentally of structure aesthetics wrinkled.
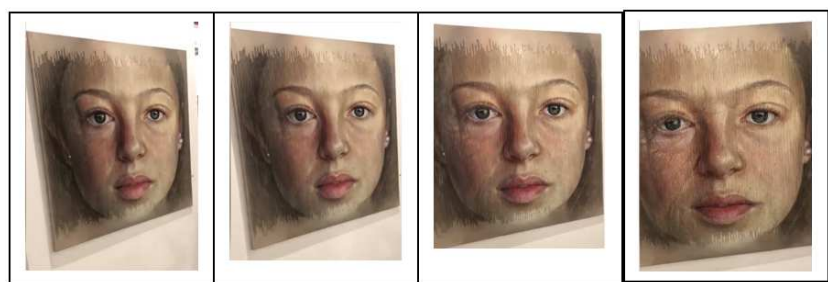

Figure 3. (from left: A, B, C, D) 'Ages" of Artist's Sergi Cadenas [1], Shrinkage in the face is graded by a known percentage of the elasticity's in the in its degrees to show different ages throw stretch potential of structure aesthetics wrinkled. https://en.wikipedia.org/wiki/Canvas [1].
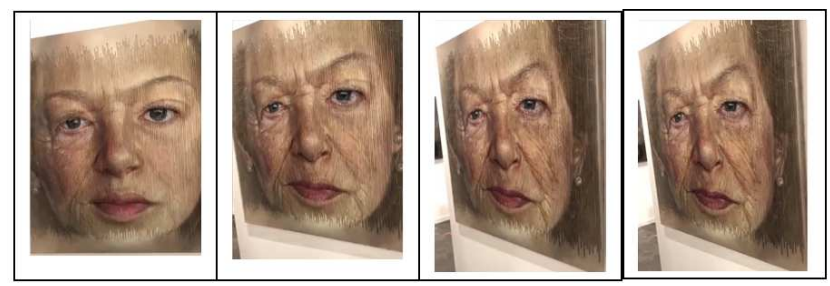

Figure 4. (from left: $E, F, G, H)$ "Ages" of artist's Sergi Cadenas [1], shrinkage in the face is graded by a known percentage of the elasticity's in the in its degrees to show different ages throw stretch potential of structure aesthetics wrinkled.. https://en.wikipedia.org/wiki/Canvas [1].

As a result, the viewing angle of the proposed system is about more than two times wider than that of the conventional system of stretch potential throw aesthetics wrinkled. Figure 3, 4 displays a movie of the observed integrated images when the observer is moving from side to side of the viewing zone in the proposed scheme

Face cod (A) stretch potential is $(0,030)$ and viewing angle are $\left(0^{\circ}\right)$. The location of the integrated image of face stretch potential and the location of the integrated image of an orange in front of the lens array.

Face cod (B) stretch potential is $(0,043)$ and viewing angle are $\left(4.2^{\circ}\right)$ the location of the integrated image of face stretch potential the location of the integrated image of an orange in front of the lens array.

Face cod $(\mathrm{C})$ stretch potential is $(0,053)$ and viewing angle are $\left(6.1^{\circ}\right)$ the location of the integrated image of face stretch potential the location of the integrated image of an orange in front of the lens array.
Face cod (D) stretch potential is $(0,062)$ and viewing angle are $\left(7.5^{\circ}\right)$ the location of the integrated image of face stretch potential the location of the integrated image of an orange in front of the lens array.

Face cod (E) stretch potential is $(0,070)$ and viewing angle are $\left(9.5^{\circ}\right)$ the location of the integrated image of face stretch potential the location of the integrated image of an orange in front of the lens array.

Face cod $(\mathrm{F})$ stretch potential is $(0,081)$ and viewing angle are $\left(13^{\circ}\right)$ the location of the integrated image of face stretch potential the location of the integrated image of an orange in front of the lens array.

Face cod $(\mathrm{G})$ stretch potential is $(0,090)$ and viewing angle are $\left(16.5^{\circ}\right)$ the location of the integrated image of face stretch potential the location of the integrated image of an orange in front of the lens array.

Face cod $(\mathrm{H})$ stretch potential is $(0,102)$ and viewing angle are $\left(20^{\circ}\right)$ the location of the integrated image of face stretch potential the location of the integrated image of an orange in front of the lens array.

We can see the different perspectives of the images of stretch potential throw aesthetics wrinkled continuously with different viewing directions. In this movie the grids of the lens array are observed because the depth of focus of the camera used to pick up the integrated image is larger than that of human. Although the existence of the grids is a demerit of the integral imaging, when human observes the integrated image, the grids behind the image are not observed so well. The camera movement may not look smooth stretch potential throw aesthetics wrinkled. However, it is not owing to the integrated images but owing to the lack of technique to videotape the image as moving the camera uniformly in horizontal direction.

The results show a remarkable enhancement of viewing angle in stretch potential throw aesthetics wrinkled. Since the lens array is curved horizontally, only the horizontal viewing angle is enhanced in this experiment. Vertical viewing angle throw stretch potential throw aesthetics wrinkled that can be enhanced similarly if we use a lens array that is also curved vertically. If spherically shaped lens array is used, the viewing angle would be enhanced in both directions. Also cause some image of stretch potential throw aesthetics wrinkled to distortion at the image boundaries when 3D images with some longitudinal depth are displayed because the deviation from the image plane in focus becomes larger. The gap mismatch might be removed if a curved wrinkled of potential screen is used instead of the flat panel display and if the elemental images stretch throw aesthetics are projected on the curved screen and integrated through the curved lens array.

For the nth elemental lens from the central elemental lens surface and compact force (we assign $n=0$ for the central elemental lens), the gap mismatch $\mathrm{G} n$ can be calculated a curved wrinkled of potential [9] as follows:

$$
G=(g+d)[\sec (2 n \theta)-1]
$$

where $g$ is the distance from the central elemental lens of surface and compact force to the display panel, $d$ is the 
distance from the lens array to the object a curved wrinkled of potential, curvature radius, and $\theta$ is given by

\subsection{Compact Force of Aesthetics Wrinkled}

Structure aesthetics wrinkled in differential geometry, deformations from the wefts on a surface are considered as a series of twisted curves which generate into a three-dimensional shape [12] in figure 6. This theory is applicable to the surface of the material in fabric buckling of structure aesthetics wrinkled, folding and drape. The differential geometry parameters can incorporate the mechanical properties of a material by relating these mechanical properties to the changes in curvature as a surface is transformed structure aesthetics wrinkled into another surface $[8,9,10,12]$.

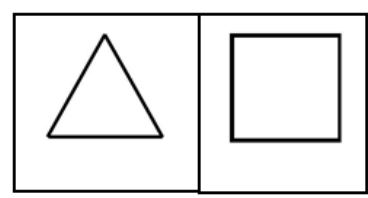

Figure 5. Triangular, Rectangular faces.

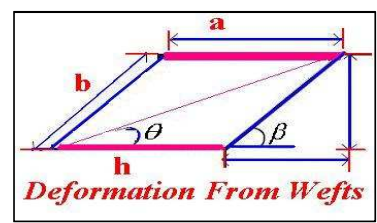

Figure 6. Square form.

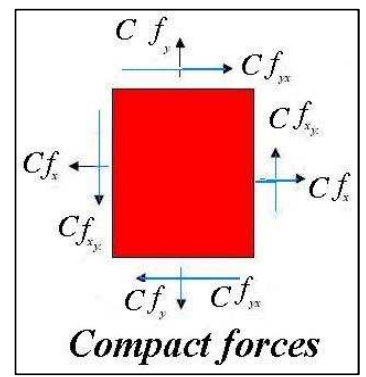

Figure 7. Square form.

Within the structural unit, the uniform deformation, and the small deformation assumption, then prescribed strain increment (x y x y] with strain calculation along any direction $[9,10]$,

$$
\begin{aligned}
\mathrm{ds}^{2}-d S^{2} & =d X^{T}\left(F^{T} F-I\right) d X=d X(2 E) d X \\
\varepsilon & =\frac{\mathrm{ds}-d S}{d S}=\frac{d X(E) d X}{(d S)^{2}}
\end{aligned}
$$

ds, dS: the length of a material line element $(\mathrm{dX})$ after and before deformation, F: deformation tensor, E: strain tensor, Strain and Force, and Strain along $\alpha$ and $\Upsilon$ fiber directions [9]

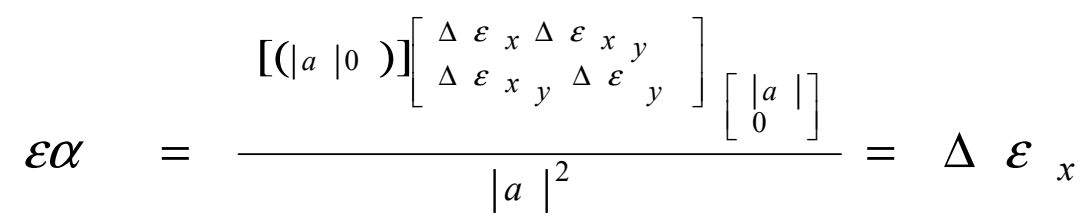

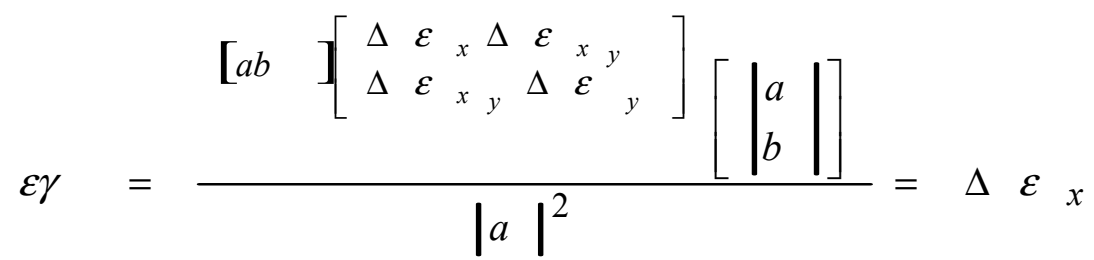

$$
\begin{aligned}
& =\frac{a^{2}}{\sqrt{a^{2}+b^{2}}} \Delta \varepsilon_{x} \frac{2 a b}{\sqrt{a^{2}+b^{2}}} \Delta \varepsilon_{x y}+\frac{b^{2}}{\sqrt{a^{2}+b^{2}}} \Delta \varepsilon_{y}
\end{aligned}
$$

Forces acting on $\alpha$ and $\Upsilon$ fiber directions [9]

$$
\begin{gathered}
C f_{\alpha}=E_{\alpha} A_{\alpha \Delta \varepsilon_{x}} \\
C f_{\gamma}=E_{\gamma} A_{\gamma}\left[\frac{a^{2}}{\sqrt{a^{2}+b^{2}}} \Delta \varepsilon_{x}+\frac{2 a b}{\sqrt{a^{2}+b^{2}}} \Delta \varepsilon_{x \gamma}+\frac{b^{2}}{\sqrt{a^{2}+b^{2}}} \Delta \varepsilon_{\gamma}\right]
\end{gathered}
$$


Forces on the Structural Unit: Compact forces of Deformation on square shape Where force acting on $\mathrm{x}$ and $\mathrm{y}$ directions, compactness, viscoelasticity, and unifying elastic material assumption $[8,9,10]$ :

$$
\begin{aligned}
& C f_{\chi}=n_{\chi}^{\alpha} C f^{\alpha}+n_{\chi}^{\gamma} C f^{\gamma} \cos \beta \\
& C f_{\chi_{\gamma}}=n_{\chi}^{\gamma} C f^{\gamma}+n_{\chi}^{\gamma} C f^{\gamma} \sin \beta \\
& C f_{\gamma}=n_{\gamma}^{\gamma} C f^{\gamma} \sin \beta \\
& C f_{\chi_{\gamma}}=n_{\chi}^{\gamma} C f^{\gamma}{ }_{+n_{\chi}^{\gamma} C f^{\gamma}} \cos \beta
\end{aligned}
$$

$n_{\chi}^{\alpha}, n_{\chi}^{\gamma}$, the number of $\alpha$ or $\Upsilon$ fiber on the boundary surface facing $\mathrm{x}$ or $\mathrm{y}$ direction, Stresses on the structural unit, calculation a crinkle distortion, and Compact Forces of Deformation on square shape $[9,10]$

$$
\mathrm{C} \mathrm{D}=\sqrt{\frac{\mathrm{S} \mathrm{P} \%}{\mathrm{CW} R / \mathrm{mm}}}+\frac{\text { warp }+W R}{W R} \%
$$

Where: CD: crinkles distortion, ST\%: stretch potential \%, CWR: crinkles width Repeat $/ \mathrm{mm}$., and

WR: Weft Repeat [11, 16, 22], compact force of 3D triangulated of canvas Double-layer woven fabric for structure aesthetics wrinkled: [9, 10], The surface area of a 3D triangulated surface can be computed as a sum of all triangle area, which is trivial application of formula [12]. However, structure aesthetics wrinkled fabric and deformations in the scan data make such calculation unreliable. Even after curve fitting to each cross section, the total area of triangulated meshes as effects between as stretch potential of spandex for structure aesthetics wrinkled [22], and the structures of canvas double- layers tend to be large than the real area. We believe that the numerical integration method is a better approach because surface area is the double integration of surface for the two canvas layers of fabrics coordinates [12], which acts as low canvas layer while changing with height Canvas layer out deformations. Structure aesthetics wrinkled of surface areas between the canvas double-layers and compact force of stretch of weft and wove structures aesthetics wrinkled [11]. For better approximation, the following formula which takes canvas layers of woven fabrics, namely $[9,10]$ :

$$
\begin{aligned}
& \text { Warp Float Distortion }=\frac{\text { weft contractio } n \text { for each float }}{\text { the warp float length }} \times 100 \\
& \mathrm{~S}_{\mathrm{D}}=100 \pi \frac{\omega \int}{4}+\frac{W F D}{S P_{W}}\left[\int \frac{K_{c}+\sum\left(h_{y}+h_{w}\right)}{4 T_{T K}}+\frac{(\rho \mathrm{y})}{(\rho \mathrm{f})}\right]
\end{aligned}
$$

Where: $\mathrm{S}_{\mathrm{k}}=$ shape Deformation. $W F D=$ Warp Floated Distortion. $T_{T K}=$ fabric thickness. $S P W, \max =$ Stretch potential. $\omega=$ width of shape. $\int=$ length of shape. $K_{C}=$ cloth cover factor. $\rho \mathrm{y}=$ yarn density. $\rho \mathrm{f}=$ fiber density., $\left(h_{y}+h_{w}\right)$ Where: $L(h)$ is the parameter of a cross sectional curve at level $h$ and $h_{2}$ are the "height" of the bottom, middle and top cross section, respectively. The perimeter is the sum of point-to-point distance a curved wrinkled of potential chord length. we describe structure aesthetics wrinkled an experimental and computational approach to determine the compact force effects of canvas stretched woven fabrics on painting surface area and volume of an inflated 3D angle-view of canvas double-layer woven fabrics we acquired inflated 3D angle-view surface of the round model 3D angle-view of canvas double-layer woven fabrics using 3D angle-view laser scanning system and computed their painting surface areas and volume with a numerical integration approach. using canvas stretched woven fabrics, containing spandex combined with variation in fabric tightness through utilizing different weaves led to producing 3D angle-view with stretch potential effects upon relaxation of fabrics without the need for heat, chemical treatment, or mechanical devices such as those used to produce crinkle effects. The eights stretch potential spandex varieties used did not show appreciable difference in regards to the $3 \mathrm{D}$ compact force effects for developed geometric model to predict painting colors/weaves contribution of each painting colored angle-view in canvas stretched woven fabrics structure. The geometric model combined with existing painting color mixing model allow the prediction of final painting color of woven fabrics constructed from colored painting. The excellent correlation between the predicted and measured values of painting color attributes for wide range of painting colors/weaves indicates that the model could be used to automate the process of color assignment to obtain angleview faces that match the artworks without human intervention. This will enable the angle-view producers to eliminate unnecessary trials and thus quickly respond to customer order and reduce the manufacturing cost of intricate structure aesthetics wrinkled fabrics. The development of the experience of drawing, painting and dealing with childhood and old age throw structure aesthetics wrinkled, Learn about the linguistic expressions used in dealing with the elderly, such as "golden age" or "third age stage" or "people in the tranquility and calm phase", which are expressions that use different from one topic to another whether it is related to medicine, social affairs or entertainment areas assigned to them or with government depart ments, and therefore they reflect the point of view of each party in dealing with the face drawing and its transformation of the elderly and the style of expression through the image to them.

Not always "golden fall" is not aging that means disease and wasting. Just as they are inevitable stages in life, some 
try to see from it the positive side, the philosophy of dealing with aesthetic unity in drawing the subject and that not a small percentage in marking the elderly have good experience, they have acquired in their practical life, and they wish to transfer it to the younger generations, from during the lessons of stretch and helping talented students in the field of drawing and coloring, the exhibition also offers some ideas and proposals on how to develop the spirit of creativity and innovation while respecting the retirement age and the requirements it needs such as calm and comfort.

\section{Conclusions}

This philosophy of structure aesthetics wrinkled is not entirely new to public opinion, as the meaning has been called that human skin shrinks like shrinkage of fabric painted on it stretch potentials of cloth at a rate of elasticity that ranges with age and the passage of time, The secret of feeling happy in drawing the advanced stages of life is the will to deal with the aesthetic unity of the subject. But we present and present this philosophy to the public in an integrated form that sees the creator, artist, and connoisseur through it a clear embodiment of the problem of drawing and coloring the stages of life that has become a concern for many, so it is not excluded that this demonstration opens a wide discussion about drawing and coloring the stages of life in the world of drawing and image technology that can benefit from it for young \& aging

\section{References}

[1] Artist's Sergi Cadenas (2019) retrieved at: https://wooarts.com/sergi-cadenas/

[2] AATCC Standard Test Method, D-79-1968.

[3] ASTM D 3776-96 standard test method for mass per unit area (Weight) of fabric.

[4] ASTM D3107-2003 (Standard Test Method for Stretch Properties of fabrics Woven Stretch Yarn).

[5] B. Javidi, S.-W. Min, and B. Lee, "Enhanced 3D color integral imaging using multiple display devices," Proc. of IEEE LEOS Annual Meeting (San Diego, CA, 2001), 491-492. 15. J.-H. Park, S.-W. Min, S. Jung, and B. Lee, "Analysis of viewing parameters for two display methods based on integral photography," Appl. Opt. 40, 5217-5232 (2001).

[6] B. Lee, S. Jung, and J.-H. Park, "Viewing-angle-enhanced integral imaging using lens switching," Opt. Lett. 27, 818-820 (2002).

[7] ElNashar E. A., Egypt. Patent, 986/2011, Patent Office, Technology Development and Scientific service Sector, Academy of scientific Research and technology, Ministry of State for scientific Research, Cairo, Egypt (2011).

[8] ElSayed A. ElNashar (2017)"Effect Of Stretch Potential On Volume Porosity And Air Permeability In Knitting Fabrics"., Applied Researches in Technics, Technologies and Education Journal of the Faculty of Technics and Technologies, Trakia University, ARTTE Vol. 5, No. 1, 2017 ISSN 1314-8788 (print), ISSN 1314-8796 (online), doi: 10.15547/artte.2017.01.003, https://sites.google.com/a/trakiauni.bg/artte/

[9] ELSAYED A. ELNASHAR (2012), “compact force using COMPACT FORCE theory of geometry shape for stretch clothes design"" УЧЕТ СИЛЫ СЖАТИЯ В ТЕОРИЯ МНОЖЕСТВ ГЕОМЕТРИИ ПРИ РАЗРАБОТКЕ РАЗЛИЧНЫХ ФОРМ ЭЛАСТИЧНОЙ ОДЕЖДЫ "Smartex-2012, the XI International Workshop "Physics of Fibrous Materials: Structure, Properties, Science Intensive Technologies and Materials, "SmarTex-2012", the Ivanovo State Textile Academy from 28 - 29 May, 2012, Russian. https://elibrary.ru/item.asp?id=22835804

[10] ElSayed A. ElNashar, (2014)" compact force using rough set theory of geometry shape for stretch clothes design" Applied Researches in Technics, Technologies and Education Journal of the Faculty of Technics and Technologies, Trakia University https://sites.google.com/a/trakia-uni.bg/artte/,. ARTTE Vol. 2, No. 2, 2014 ISSN 1314-8788 (print), ISSN 1314-8796 (online)

[11] Elsayed A. ELNASHAR, Arafa A. NASEF, Elsayed M. SALEEM\& Yan LIU, A Unified Stretch Theory of Ancient Clothes on Some Basic Knowledge For Fashion Dresses Design,; 5th International October 03rd to 06th 2010, DUBROVNIK, CROATIA, international textile, clothing \& design conference - Magic World of Textiles. 2010.

[12] ElSayed a. ElNashar, victor kuzmichev \& N. A. Sakharova (2011)."Fitting stretch model of three-dimensional for simulating apparel surface", 1st Smartex-Egypt 2011 (world textiles conference), November, 22nd-24th 2011, Kafrelsheikh university, Egypt.

[13] ELSAYED AHMED ELNASHAR (2019) "Woven Seamless of Clothes between Ancient Egyptian History and Future", Latest Trends in Textile and Fashion Designing (LTTFD), Trends in Textile \& Fash Design. Volume 3 - Issue 4 Copyrights@ Elsayed Ahmed Elnashar. Received: November 08, 2019 Published: November 18, 2019. DOI: 10.32474/LTTFD.2019.03.000169

https://lupinepublishers.com/fashion-technology-textileengineering/pdf/LTTFD.MS.ID.000169.pdf

[14] Elsayed Ahmed Elnashar (2019) Which Languages That Colors Speaking in Fashion Textiles/Clothes, Journal of Textile Science \& Fashion Technology, Volume 1 - Issue 4, $2019 . \quad$ JTSFT.MS.ID.000524. https://irispublishers.com/jtsft/pdf/JTSFT.MS.ID.000524.pdf

[15] ElSayed ELNASHAR, (2019)" Contemporary Fashion and its Artistic Values in the Fifth Generation of Technology", Jornal of "Latest Trends in Textile and Fashion Designing (LTTFD)", https://lupinepublishers.com/fashion-technology-textileengineering/pdf/LTTFD.MS.ID.000164.pdf

[16] ElSayed ElNashar, Fatma Kalaoglu, Mohamed Hashem.; Crinkles Approach for Development of Aesthetics Wrinkled Fabrics Containing Spandex. XIII International Workshop "Physics of Fibrous Materials: Structure, Properties, Science Intensive Technologies and Materials" (SMARTEX-2010) that take place in the Ivanovo State Textile Academy (Russia) 2426 May, 2010.

[17] ElSyaed ElNashar, Tamer Hamouda, and Abdel-Fattah M. Seyam [2008]. Three-Dimensional Effects Using Yarns Containing Spandex, 1st international conference of applied arts-Domitta, EGYPT. (Applied arts future Expectations), 1315 May 2008. 
[18] ElSyaed ElNashar, Tamer Hamouda, and Abdel-Fattah M. Seyam [2008]. Three-Dimensional Effects Using Yarns Containing Spandex and Influence of Spandex Type, 1st international conference of Applied arts-Domitta, EGYPT. (Applied arts future Expectations), 13-15 May 2008

[19] Gardner's Art through the Ages, 14e, (2019) chapter 28 Impressionsm, Post-Impressionism, Symbolism; Europe and America, 1870 to 1900 , selection form; Chapter 34 Japam. 1335 to $1980 . \quad$ Retrieved at: https://www.fsusd.org/cms/lib03/CA01001943/Centricity/Do main/2087/Chapter\%2028\%20Impression\%20Post\%20Impres sionism.pdf

[20] Gordon, Dillian, (2003) National Gallery Catalogues (new series): The Fifteenth Century Italian Paintings, Volume 1, 2003, ISBN 1857092937

[21] J.-S. Jang and B. Javidi, "Improvement of viewing angle in integral imaging by use of moving lenslet arrays with low fill factor," Appl. Opt. 42, 1996-2002 (2003).

[22] Kavita Mathur, ElSayed ElNashar, Peter Hauser, and AbdelFattah M. Seyam, [2008]".stretch potential of woven fabrics containing spandex.' International Workshop "Physics of Fibrous Materials: Structure, Properties, Science Intensive Technologies and Materials" (SMARTEX-2008) that take place in the Ivanovo State Textile Academy (Russia) 26-27 May, 2008.

[23] National Museum (Muzeum Narodowe)".(2013) www.warsawtour.pl. Archived from the original on 7 October 2013. Retrieved 20 October 2013. the largest Polish painting Battle of Grunwald'by Jan Matejko (426 x $987 \mathrm{~cm})$.
[24] Oxford Dictionaries. Oxford (2014) University Press. Retrieved https://en.wikipedia.org/wiki/Canvas\#cite_note-3

[25] S. Jung, J.-H. Park, H. Choi, and B. Lee, "Wide-viewing integral three-dimensional imaging by use of orthogonal polarization switching," Appl. Opt. 42, 2513-2520 (2003).

[26] S.-H. Shin and B. Javidi, "Viewing-angle enhancement of specke-reduced volume holographic threedimensional display by use of integral imaging," Appl. Opt. 41, 5562-5567 (2002).

[27] S.-W, Min, S. Jung, J.-H. Park, and B. Lee, "Study for wideviewing integral photography using an aspheric Fresnel-lens array, " Opt. Eng. 41, 2572-2576 (2002).

[28] S.-W. Min, B. Javidi, and B. Lee, "Enhanced threedimensional integral imaging system by use of double display devices," Appl. Opt. 42, 4186-4195 (2003).

[29] Stiffness for stretch woven fabrics according to Standard Test Method ASTM. D1388-96 (Standard Test Method for Stiffness of fabrics).

[30] The Online Etymology Dictionary". (2012) Etymonline.com. Retrieved 2012-05-05. https://en.wikipedia.org/wiki/Canvas\#cite_note-2

[31] Yunhee Kim, Jae-Hyeung Park, Heejin Choi, Sungyong Jung, Sung-Wook Min, and Byoungho Lee () Viewing-angle-enhanced integral imaging system using a curved lens array, (C) 2004 OSA 9 February 2004 / Vol. 12, No. 3 / OPTICS EXPRESS 422. 